Portland State University

PDXScholar

\title{
Methods for Correcting Topographically Induced Radiometric Distortion on Landsat Thematic Mapper Images for Land Cover Classification
}

David Michael Rosen

Portland State University

Follow this and additional works at: https://pdxscholar.library.pdx.edu/geog_masterpapers

Part of the Geographic Information Sciences Commons, Physical and Environmental Geography Commons, and the Remote Sensing Commons Let us know how access to this document benefits you.

\section{Recommended Citation}

Rosen, David Michael, "Methods for Correcting Topographically Induced Radiometric Distortion on Landsat Thematic Mapper Images for Land Cover Classification" (2005). Geography Masters Research Papers. 12.

https://pdxscholar.library.pdx.edu/geog_masterpapers/12

10.15760/geogmaster.12

This Paper is brought to you for free and open access. It has been accepted for inclusion in Geography Masters Research Papers by an authorized administrator of PDXScholar. Please contact us if we can make this document more accessible: pdxscholar@pdx.edu. 
Methods for Correcting Topographically Induced Radiometric Distortion on Landsat Thematic Mapper Images for Land Cover Classification

David Michael Rosen

Submitted for partial fulfillment of Master of Science degree in Geography Portland State University

Approved by
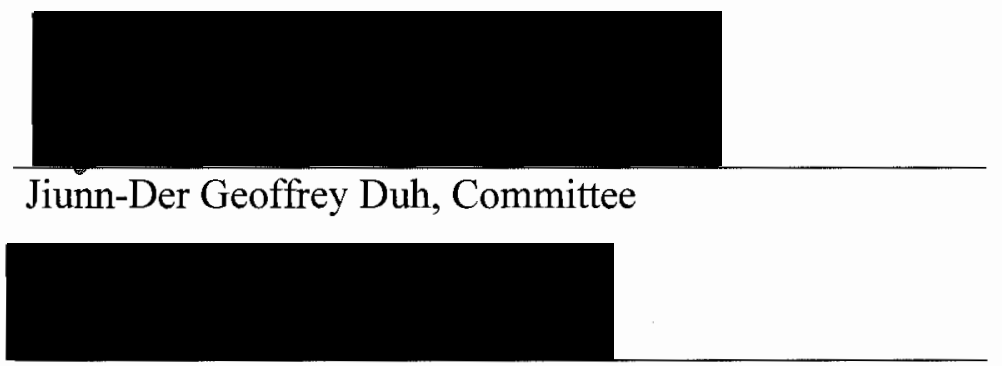

Martha Works, Faculty Advisor

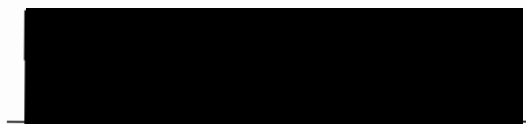

Thomas Harvey, Department Chair 


\begin{abstract}
An abstract of the research paper of David Michael Rosen for the Master of Science in Geography presented June 7, 2005.
\end{abstract}

Title: Methods for Correcting Topographically Induced Radiometric Distortion on Landsat Thematic Mapper Images for Land Cover Classification.

Satellite imagery is commonly used to study land-use, land-cover change in mountainous areas. Classification of land-cover types is particularly difficult in this type of terrain because topography affects the spectral response of surface features. Several techniques have been developed to help compensate for this topographic effect and to increase classification accuracy.

The purpose of this study is to compare topographic correction methods to determine which produces the most accurate results. Method 1 does not use any topographic correction, serving as a control. Method 2 is based on the Lambertian model, and uses topographical data as variables in an equation. Method 3 adds an aspect band and a vegetation index band to the image prior to classification. Both of these latter methods produced significantly more accurate results than the control (method 1) in the classification of agricultural lands, but did not improve accuracy in forestland classification. 


\section{TABLE OF CONTENTS}

PAGE

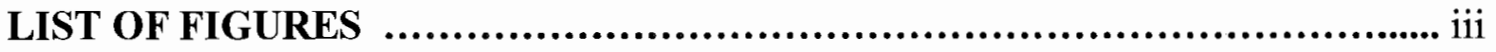

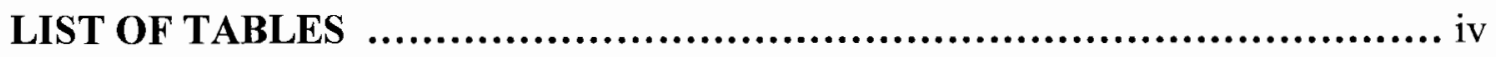

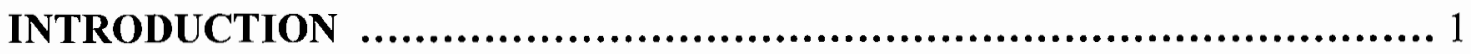

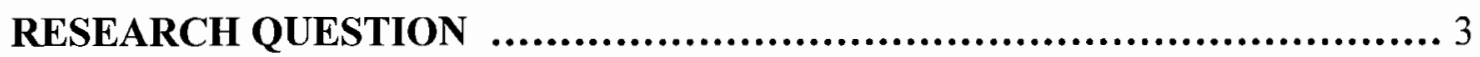

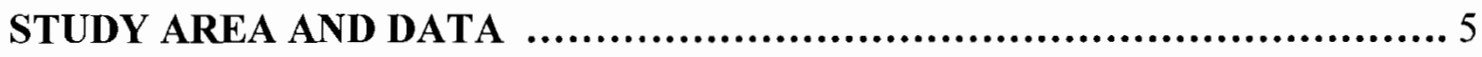

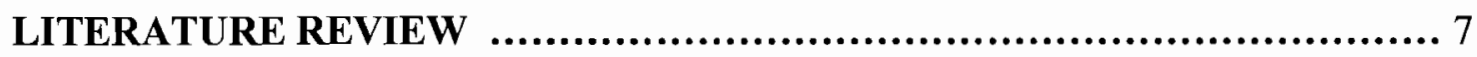

COSINE CORRECTION USING THE LAMBERTIAN MODEL ............. 7 NON-LAMBERTIAN COSINE CORRECTION....................... .8

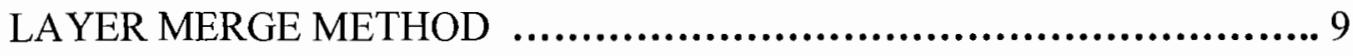

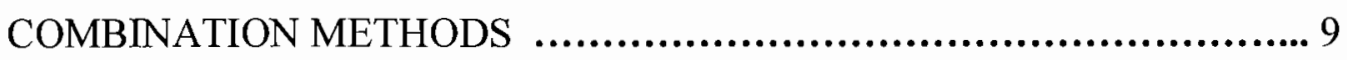




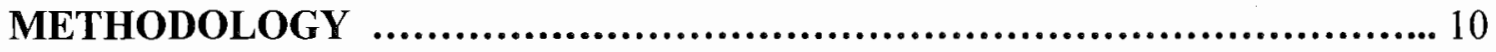

CLASSIFICATION SCHEME $\quad$................................................... 12

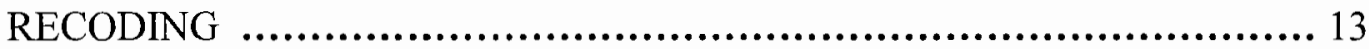

BASIC METHOD - METHOD 1 ..............................................13

COSINE CORRECTION METHOD - METHOD 2 ........................... 13

LAYER MERGE METHOD - METHOD 3 ...................................14

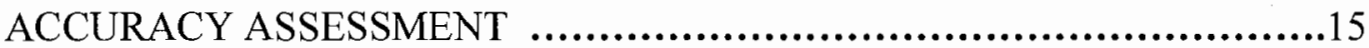

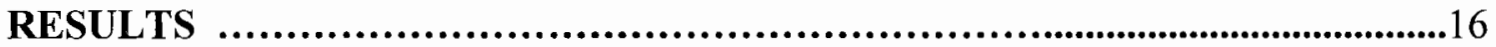

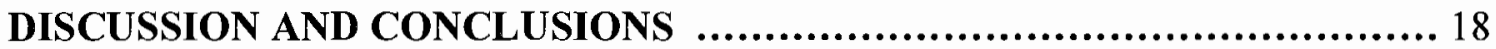

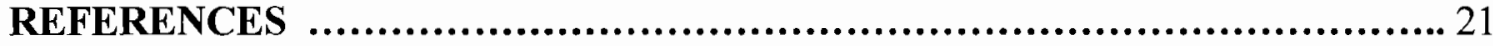




\section{LIST OF FIGURES}

FIGURE

PAGE

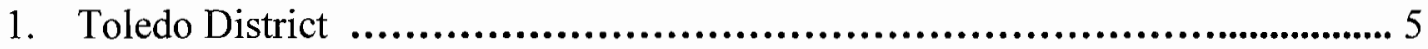

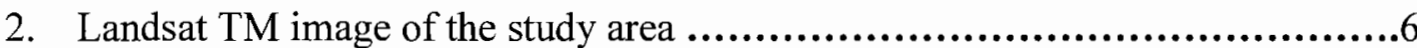

3. Aspect layer with data of areas with slope less than $10 \%$ removed $\ldots \ldots \ldots \ldots \ldots . .15$

4. Classified thematic maps based on (a) uncorrected spectral bands and (b) layer-merged bands of spectral, aspect and TNDVI $\ldots \ldots \ldots \ldots \ldots \ldots \ldots \ldots . . . . . . .17$

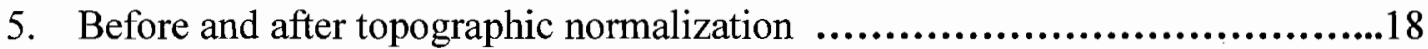

6. Class confusion - Method 2 ..........................................................19 


\section{LIST OF TABLES}

TABLE

PAGE

1. Accuracy Assessment 16 


\section{INTRODUCTION}

In tropical regions, remote sensing is used to study land-use, land-cover (LULC) change, and deforestation (Roy et al. 1991; Rey-Benayas and Pope 1995; Foody et al. 1997; Colby and Keating 1998; Tucker and Townshend 2000). While much of the research on tropical deforestation has focused on global climate change, a wide range of environmental impacts has been identified. These include: loss of biological diversity, soil degradation, and a decrease in the ability of biological systems to support human needs (Lambin et al. 2003). The dynamics of LULC change in the tropics are complex, and using remote sensing to gain a clearer understanding of the patterns and processes can help to guide sustainable development strategies and environmental research (Green et al.; Moran and Brondizio 1994; Turner et al. 1994; Lambin 1997; Tucker and Townshend 2000).

This paper evaluates satellite image classification approaches with different topographic correction methods in the Toledo District of Belize. It fits within the context of a larger inter-disciplinary project studying LULC change in the region (Emch et al. 2005). The Toledo District was chosen as a study area because it contains some of the largest tracts of pristine evergreen forest remaining in Central America (Parker et al. 1993). 
These forests are threatened because of increases in population, and concessions granted to international timber companies to $\log$ nearly 75,000 hectares (Emch et al. 2005). The terrain of Toledo's Maya Mountains also makes the region conducive to the studies of topographic effects on image classification.

While LULC classification of areas with flat terrain is relatively straightforward, mountainous areas create challenges, including illumination variation introduced by topographic effect, which must be corrected to produce accurate classification. The topographic effect is defined as the variability of spectral values within a particular land cover class, resulting from illuminative variations associated with slope and aspect (Jensen 1996). The illumination of a particular pixel is dependent on its relative orientation to the position of the sun (Jensen 1996). This effect is exacerbated by conditions of low sun angle and extreme topographic relief (Civco 1989).

Several methods have been developed to normalize or correct the effect of topography and reduce the impact of shadows created by topographical features. They include band ratios, cosine correction, layer merge and various combinations of these methods (Teillet 1986; Leprieur et al. 1988; Civco 1989; Colby 1991; Gu and Gillespie 1998; Dorren et al. 2003; Wulder et al. 2004). These methods can be grouped into two broad categories: those using band ratios and those that require digital elevation models (DEMs). Band ratio methods do not require additional data and are the easiest to implement. These methods are based on the assumption that reflectance values will increase or decrease proportionately between the two ratio bands. Calculating the quotient between the two bands will compensate for the topographic effect (Colby 1991). 
Numerous topographic correction methods use DEMs, and they can be grouped into three main categories: Cosine correction based on the Lambertian model, nonLambertian cosine correction, and layer merge methods that add topographical variables as separate bands to the satellite image. The methods that use the Lambertian model are based on the assumption that surface features reflect incoming solar radiation equally in all directions (Teillet 1986). The non-Lambertian model assumes that surface features do not reflect light equally in all directions, and that the amount of reflected light is influenced by sensor and surface geometry (Leprieur et al. 1988, Colby and Keating 1998). The third category combines ancillary topographical data with the image to improve the clustering process in classification (Strahler 1981; Dorren et al. 2003; Wulder et al. 2004).

\section{RESEARCH QUESTION}

For this study, I compared three unsupervised classification methods to determine which method provides the best accuracy in classifying land cover in the rugged terrain of the Toledo District of southern Belize (Figure 1). Method 1, titled the basic method does not use any topographic correction. Method 2 is a cosine correction method based on the Lambertian reflectance model. Method 3 is a layer merge method, which adds two bands to the satellite image, an aspect band, and a vegetation index band. These bands are added to the image prior to classification. Classification is the process of categorizing all pixels in a digital image into themes or classes. A supervised classification scheme is used when there is previous information about the identity and location of some of the 
classes, known as a priori information. This data is obtained through fieldwork, personal experience or analysis of high-resolution aerial photos. In the absence of such information an unsupervised classification scheme is used, whereby classes are created solely by grouping together pixels with similar spectral values (Jensen 1996). Unsupervised classification was used for this study because there is no a priori data. The research question is: Which method provides the highest classification accuracy, and is the most effective at differentiating between forest and non-forest land cover classes? 


\section{STUDY AREA AND DATA}

The study area is located in the Toledo district of southern Belize (Fig.1)

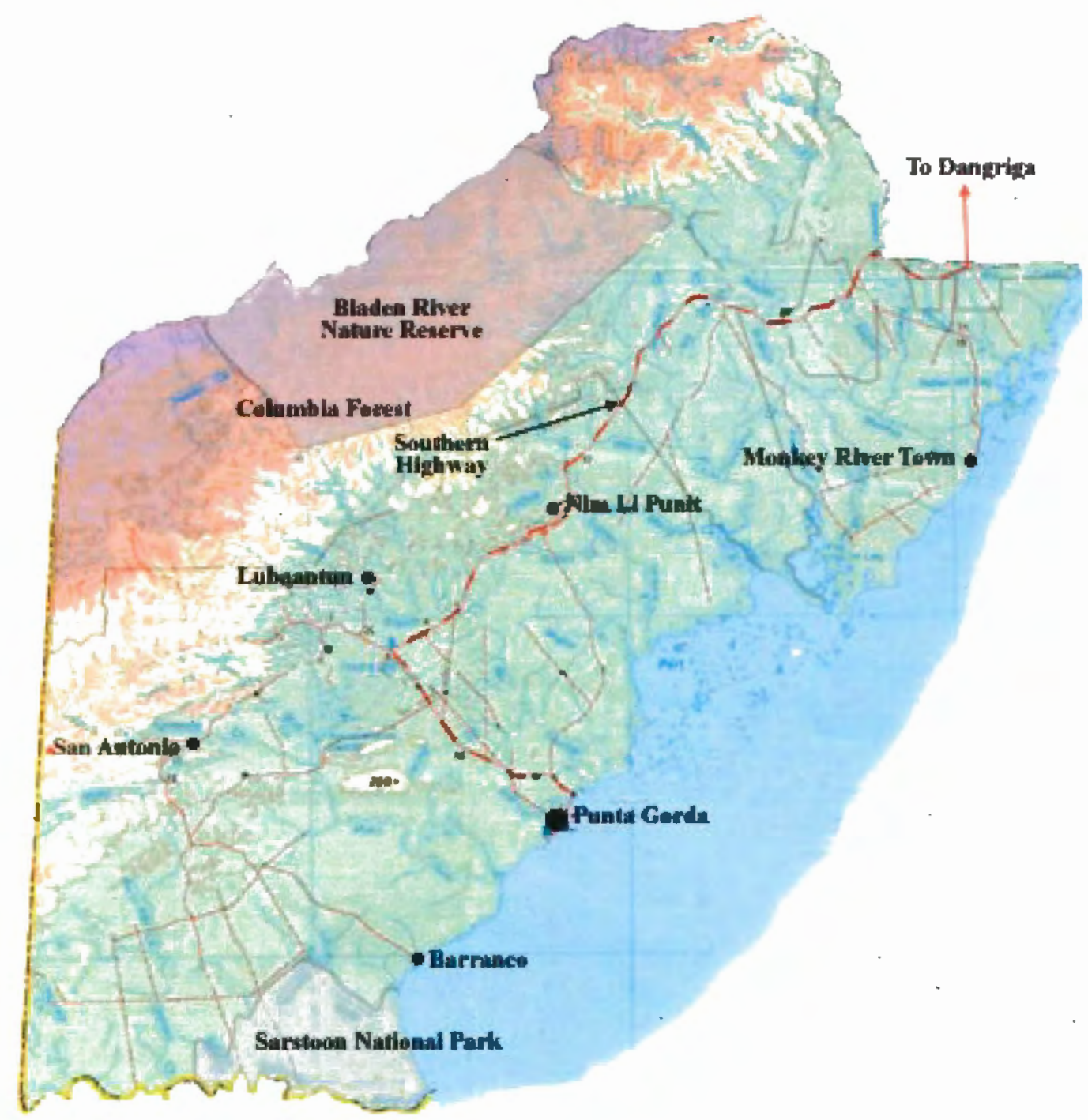

Figure 1. Toledo District

The Toledo District covers an area of approximately 4,421 square

Kilometers. The Maya Mountains form the northern border, Guatemala lies to the west and the Caribbean is to the east. 
The extent of the study area was chosen to include a variety of terrain features and land cover classes (Figure 2). Landsat TM imagery has a resolution of 30 meters and contains 7 bands.

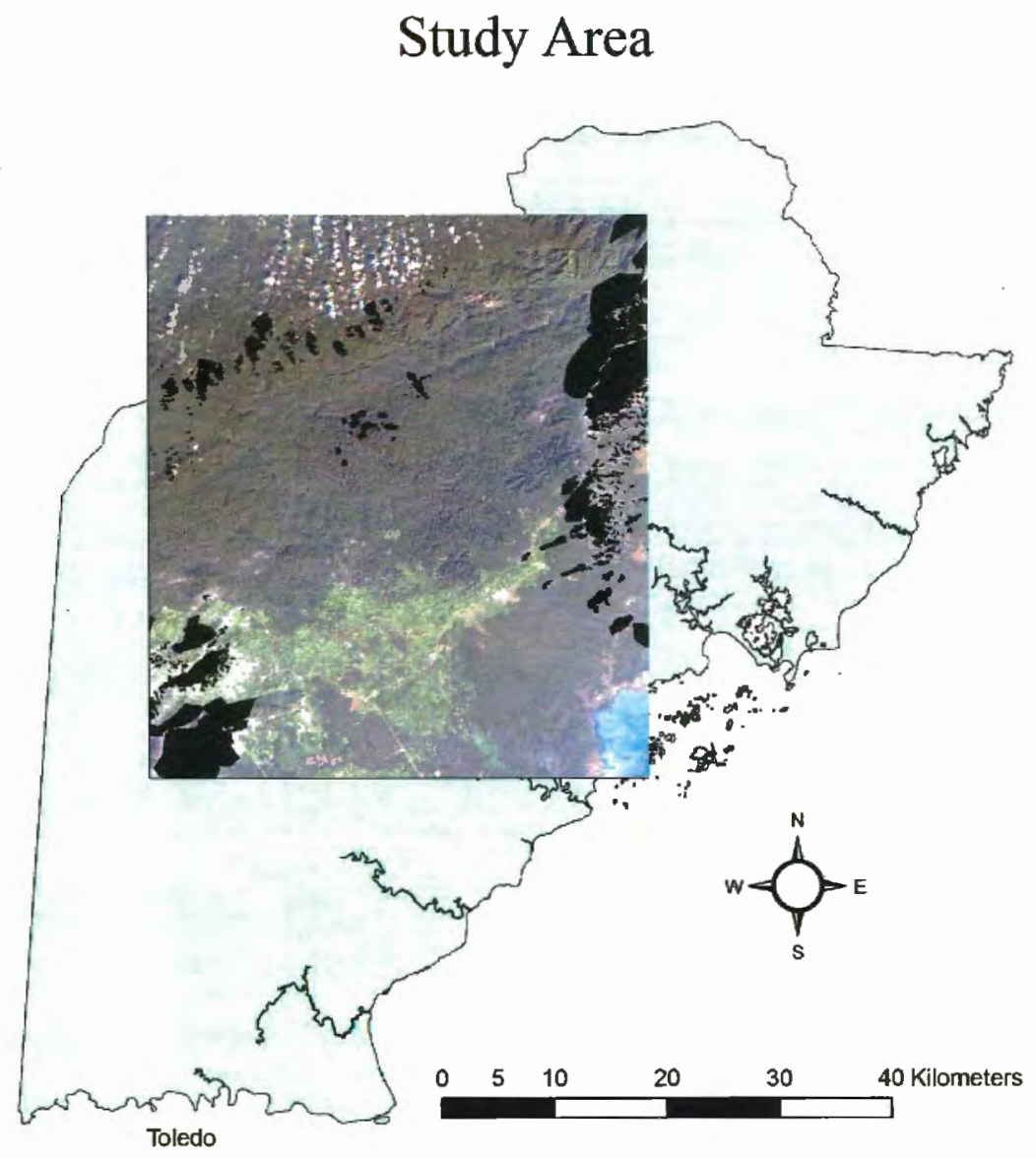

Figure 2. Landsat TM image of the study area 


\section{LITERATURE REVIEW}

This section provides an overview of some of the different topographic correction methods. These methods include cosine correction, layer merging, and methods which combine more than one approach. Although the goal of the methods is the same, they vary in difficulty of implementation, needs for additional data, and effectiveness in particularly steep areas.

\section{COSINE CORRECTION USING THE LAMBERTIAN MODEL}

The Lambertian model assumes that surface features reflect incoming solar radiation equally in all directions, and that diffuse surfaces are equally bright regardless of the observation angle. Any variations in surface brightness are a result of the differences in the angle of incoming solar radiation in respect to the surface (Colby and Keating 1998). The following formula is used for this method:

$$
B V \text { normal } \lambda=B V \text { observed } \lambda / \cos i
$$

Where: $B V$ normal $\lambda=$ normalized brightness values, $B V$ observed $\lambda=$ observed brightness values, and $\cos i=$ cosine of the incidence angle (Erdas 2003).

Although this method has been used extensively for topographic normalization, there are drawbacks and limitations with this technique. Studies have shown that normalization using the Lambertian model may only be valid for slopes less than $25^{\circ}$ and with a restricted range of incident and exitant angles (Smith et al. 1980). Other studies have shown that this method may overcompensate for the topographic effect, producing a 
result where north-facing slopes (northern hemisphere) actually appear brighter than south-facing slopes (Civco 1989; Colby 1991).

\section{NON-LAMBERTIAN COSINE CORRECTION}

The non-Lambertian model is based on the premise that the amount of reflected light is influenced not only by the angle of incidence but also by sensor and surface geometry. This type of reflection is expressed mathematically by the bi-directional reflection distribution function (BRDF). The Minnaert constant is used in this normalization algorithm. This constant developed in 1941 has been utilized in the analysis of lunar surfaces, to describe surface roughness (Justice and Holben 1979). This method uses the following formula:

$$
L(\lambda, \mathrm{e})=L_{n} \cos ^{\mathrm{k} \lambda} i \cos ^{\mathrm{k} \lambda-1} e
$$

Where $L$ is the pixel radiance, $\lambda$ is the wavelength, $e$ is the exitance angle, $\mathrm{k}$ is the Miineart constant, $i$ is the incidence angle, and $L_{n}$ is the normalized radiance that would occur when $i=e=0^{\circ}$ (i.e., both the sensor and the sun were at zenith above a flat surface) (Smith et al 1980). Variability of surface roughness between different cover types creates an inherent challenge in employing this method. Ideally, a different Minneart constant would be calculated for each cover type to accurately reflect the roughness for that type (Tokola 2001). This would require a priori knowledge of the land cover classes, which often is not available prior to classification. Techniques have been developed, which calculate a generalized constant for the entire image by creating a topographically diverse sample of the most dominant cover types (Colby et al. 1998; Hale 
and Rock 2003). Non-Lambertian normalization methods have proven to be more effective than Lambertian methods in modeling the complex optical behavior of most surfaces. In addition, good results have been obtained even in areas with high topographic relief (Colby 1991; Colby et al. 1998; Hale and Rock 2003). On the other hand, non-Lambertian methods are considerably more complex to implement, particularly with limited ancillary or ground truth data.

\section{LAYER MERGE METHOD}

Incorporating terrain data as additional bands with an image may help to produce a more accurate land cover classification. This method is particularly useful for unsupervised classification when there is no a priori data available, and is based on the assumption that terrain will affect the spectral appearance of vegetation types. Utilizing a composite image in an unsupervised clustering procedure essentially has the effect of partitioning measurement space so that sets of spectrally similar pixels will be subdivided according to ranges of elevation, slope and aspect. Unlike the previous methods, the goal of this process is not to normalize the spectral response of land cover classes, but to improve clustering by addressing the shadowing effects caused by topographical features (Strahler 1981).

\section{COMBINATION METHODS}

Several researchers have increased land cover classification accuracy by combining different methods. One technique combined non-Lambertian cosine correction with the addition of a DEM as an additional band. The addition of the DEM 
increased the overall accuracy of their classification to $73 \%$ as compared to $64 \%$ using just topographic correction. When classification was performed without any correction or the addition of the DEM, accuracy was only $45 \%$ (Dorren et al. 2003).

Another method used elevation data as an additional band, but improved accuracy by pre-stratifying the image into shadowed and non-shadowed areas prior to classification. This pre-stratification procedure was done by calculating the angle of incidence for each pixel, and subsequently using that information to identify shadowed

and non-shadowed areas. For this particular region any pixels with an angle of incidence less than $34 \%$ were designated as shadowed. Results showed that the addition of elevation data alone did not significantly increase accuracy when compared with the control method which used a standard clustering algorithm. Accuracy improved only $1.2 \%, 69.9 \%$ as compared with $68.7 \%$. On the other hand, addition of elevation data combined with shadow stratification improved accuracy to $81.1 \%$ (Wulder et al. 2004).

\section{METHODOLOGY}

The objective of this research is to compare the effectiveness of two topographic correction methods, cosine correction based on the Lambertian model, and layer merge. The method based on the non-Lambertian model was not used in this study because of the absence of ground truth or ancillary data.

First, clouds were masked on the original image. For method 1, this was the only pre-processing step performed before classification. Methods 2 and 3 included additional processing which is described below. The classification scheme used was the same for 
all three methods. The classes are forest, agriculture, bare ground, wetlands, open water, urban, and clouds. Error matrices were generated for each method and compared.

Although the image was chosen carefully to minimize the number of clouds in the study area, it is inevitable that some clouds still remain in the image. Any clouds and cloud shadows that remain were masked out since it is impossible to determine land cover classes for those pixels. At first, an unsupervised classification was attempted to try to separate out spectral values that represented clouds and their shadows. However, there was too much confusion between clouds and roads, and cloud shadows and ridgetops to produce an accurate result. As a result, each cloud was manually digitized, producing an Area of Interest (AOI) that included all the clouds in the study area. The final step was to create a mask using the ERDAS mask tool. Any clouds in the images were assigned a value of zero and were excluded from the classification process.

Unsupervised classification is used when there is no a priori or ground truth data available. The method is also called clustering because it identifies natural groupings of pixels in an image when they are plotted in feature space. The clustering algorithm used in this study is called The Iterative Self-Organizing Data Analysis Technique (ISODATA). A cluster is assigned for each pixel in the image based on the minimum spectral distance. The user specifies the number of clusters or classes, and the number of iterations. During the first iteration of the ISODATA algorithm, the mean of each cluster is arbitrarily determined. A new cluster mean is calculated with each iteration, based on the actual spectral values of the pixels in the cluster. The process continues to run until there is little change between iterations (Erdas 2003). For this study, 120 clusters were generated using a maximum of 100 iterations. The ISODATA algorithm identifies 
clusters based on spectral values, but the user determines what land cover classes these clusters represent on the ground. In the section below, I describe the classes that were used in this study.

\section{CLASSIFICATION SCHEME}

Seven classes were identified in the study area: forest, agriculture, bare ground, wetlands, open water, urban, and clouds. The forest class includes all forested areas and does not differentiate between lowland and submontane areas. The agriculture class is differentiated from forest using both spectral value and texture criteria. Bare ground areas are identified in the initial classification process, but are combined with agriculture during recoding based on the assumption that they largely represent fallow fields. The urban class represents obviously developed areas and main roads. Smaller roads may be placed into the bare ground class but can be distinguished because of their linear nature. The cloud class includes any clouds that remained after the cloud masking process.

A high percentage of land cover in the study area falls into the forest and agriculture classes. Determining which classification method best reduces topographic effects and distinguishes between these two main classes is the main focus of this study. On the other hand, the methods may differ in their ability to distinguish between the other minor land cover classes. As a result, instead of reducing the final classes to just forest and non-forest, these other classes were included so that these types of patterns could be observed. These minor classes were not included in the creation of random points for accuracy assessment and the resulting error matrices. 


\section{RECODING}

Recoding is done on all three classification methods to produce the final thematic land cover maps containing only six classes. Although similar clusters are designated with the same name, when they are evaluated, they remain as distinct classes until they are recoded. For example, 92 of 120 clusters were designated as forest. Recoding combines these clusters to create one forest class. Recoding is also used to combine insignificant classes into a different class. As described above, bare ground was recoded into the agriculture class.

\section{BASIC METHOD - METHOD 1}

Method 1 consists of a standard classification without any steps taken to correct or normalize for topographic effects. This method serves as a control or baseline for the study so that improvements in accuracy using the other methods can be realistically gauged.

\section{COSINE CORRECTION METHOD - METHOD 2}

The Topographic Normalize function in Erdas Imagine software was used for this process, which is based on the Lambertian model. A DEM, solar elevation, and azimuth information are required to run the process. The solar elevation and azimuth data are found in the header file of the image. Normalized brightness values are produced using the following equation: 
$B V$ normal $\lambda=B V$ observed $\lambda / \cos i$

Where:

$B V$ normal $\lambda=$ normalized brightness values

$B V$ observed $\lambda=$ observed brightness values

$\cos i=$ cosine of the incidence angle

The incidence angle is defined from:

$\cos i=\cos (90-\theta \mathrm{s}) \cos \theta \mathrm{n}+\sin (90-\theta \mathrm{s}) \sin \theta \mathrm{n} \cos (\Phi \mathrm{s}-\Phi \mathrm{n})$

Where:

$i=$ the angle between the solar rays and the normal to the surface

$\theta \mathrm{s}=$ the elevation of the sun

$\Phi_{\mathrm{S}}=$ the azimuth of the sun

$\theta \mathrm{n}=$ the slope of each surface element

$\Phi \mathrm{n}=$ the aspect of each surface element

If the surface has a slope of 0 degrees, then aspect is undefined and $i$ is simply90- $\theta$ s (Erdas 2003).

\section{LAYER MERGE METHOD - METHOD 3}

This method entails adding two extra bands to the satellite image before running the ISODATA algorithm. The first extra band added is an aspect band which was thresholded to eliminate any areas with a slope of less than $10 \%$. Aspect information on relatively flat areas is unnecessary for this study because there are no shadows there to affect the spectral values. This band was generated using the following steps:

1. Resample DEM from 90 meter cell size to 30 meter.

2. Generate aspect and slope data layers from DEM.

3. Threshold aspect layer using conditional statement so that areas with slopes of less than $10 \%$ are masked (Figure 3 ) 


\section{Aspect Layer}

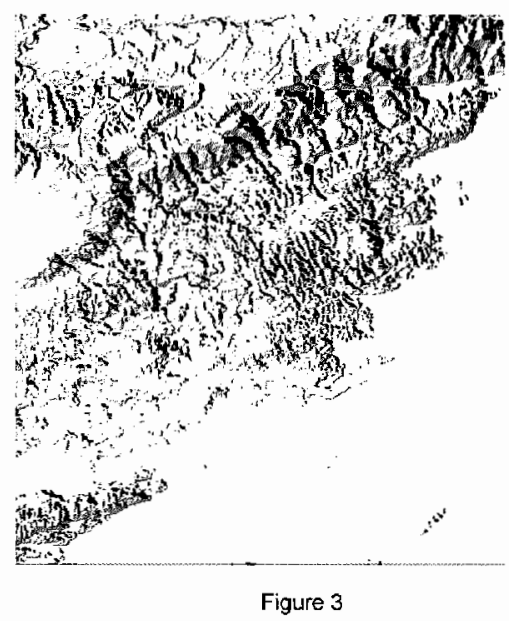

Figure 3. Aspect layer with data of areas with slope less than $10 \%$ removed.

The second extra band is generated from the Transformed Normalized Difference Vegetation Index (TNDVI). The chlorophyll in plant leaves absorbs the visible red light for use in photosynthesis and the leaves reflect near-infrared light. In general, if there is much more reflected radiation in near-infrared wavelengths than in visible wavelengths, then the vegetation in that pixel is likely to be dense and may contain some type of forest. This layer was created using the following equation:

$\sqrt{[}($ Band $4-$ Band 3) / Band $4+$ Band 3) +0.5$]$.

\section{ACCURACY ASSESSMENT}

Error matrices were created for each method and compared. One hundred random points were generated by the Erdas Imagine software. Ideally, a priori information is used to designate the class values of these points, known as reference values. Visual interpretation was used to designate the reference values since no a priori data was 
available. The error matrix compares the reference class values to the assigned class values. The accuracy assessment shows the percentage of accuracy based on the results of the error matrix (Erdas 2003).

\section{RESULTS}

The layer merge method (method 3) and topographical normalization method (method two) produced similar accuracies in classifying both agriculture and forest. Both of these methods were significantly better at identifying agriculture (73-75\%accuracy) than the basic method (58\% accuracy). All three methods resulted in similar accuracies in classifying forest (97-99\%) (Table 1).

\begin{tabular}{|l|c|c|c|}
\hline \multicolumn{1}{|c|}{ Method } & Forest & Nonforest & Overall \\
\hline Method 1 (Basic) & 98.77 & 57.89 & 91 \\
\hline Method 2 (Cosine correction) & 97.5 & 75 & 93 \\
\hline Method 3 (Layer merge) & 96.63 & 72.73 & 94 \\
\hline
\end{tabular}

Table 1. Accuracy Assessment

Additional conclusions can be drawn about the three methods through qualitative visual analysis, which are not apparent from the error matrices. Error matrices do not necessarily reflect class confusion that remains in the thematic image, particularly when random sample size is small and there is no ground truth data. While both methods two and three show an improvement in classifying mountainous areas, the effects of topography are still evident in all three methods. This can be seen by comparing areas of lowland forest with submontane forest. There is very little confusion between land cover 
types in the lowland forest areas for all three methods. Although method 1 showed excellent accuracy in classifying forest there is substantial confusion with agriculture in mountainous areas (Figure 4a) especially when compared to method 3 (Figure 4b).

(a)

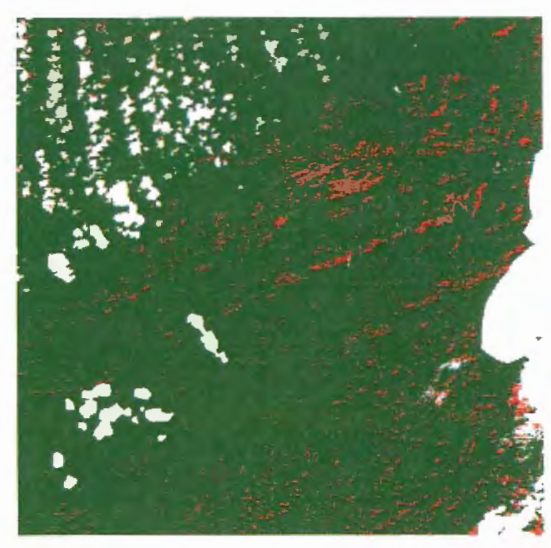

(b)

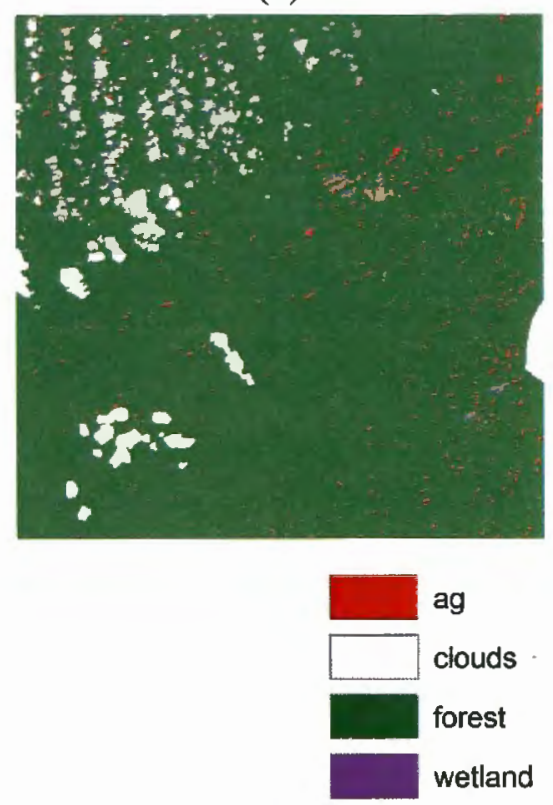

Figure 4. Classified thematic maps based on (a) uncorrected spectral bands, and (b) layer-merged bands of spectral, aspect and TNDVI.

The drawbacks of method 2 are also evident, though not indicated in the error matrix. The darkest pixels in the image are white after normalization (Figure 5). This effect illustrates the shortcomings of cosine correction using the Lambertian assumption, whereby areas of the image that are weakly illuminated are brightened disproportionately (Jensen 1996). 
(a)
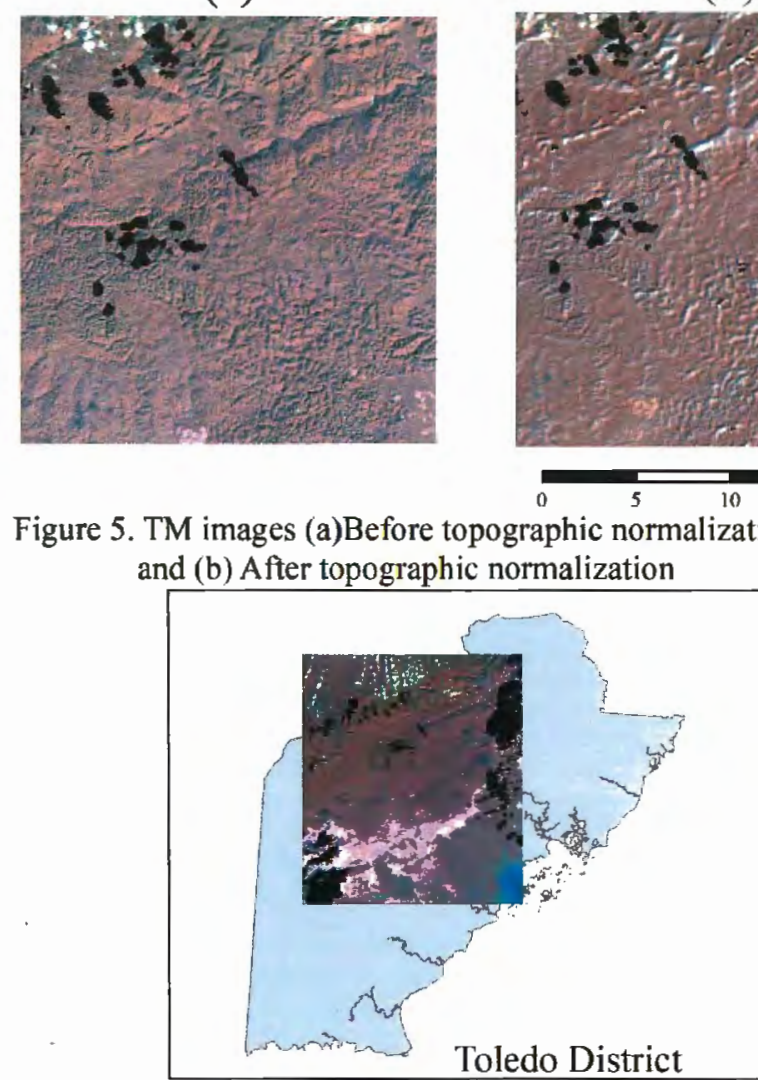

(b)

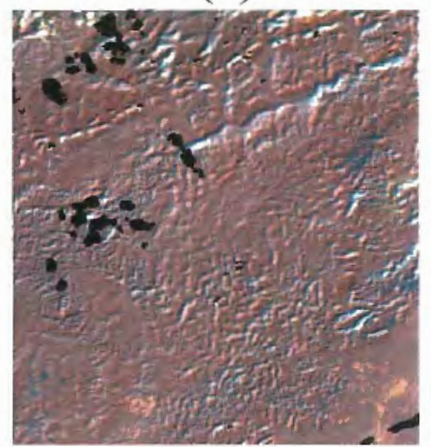

(5)

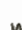

w

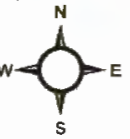

\section{DISCUSSION AND CONCLUSIONS}

The layer merge method (method 3) produced the best results of the three

methods, reducing topographic effects and minimizing confusion between forest and agricultural classes. Although the topographic normalization method (method 2) had high statistical accuracy, it still appears that many pixels in forested areas were misclassified. Figure 6 shows an area of the classified image for method 2 that appears totally forested in the TM image. It is evident that significant numbers of pixels were misclassified. This pattern is particularly apparent in the steepest parts of the study area. 


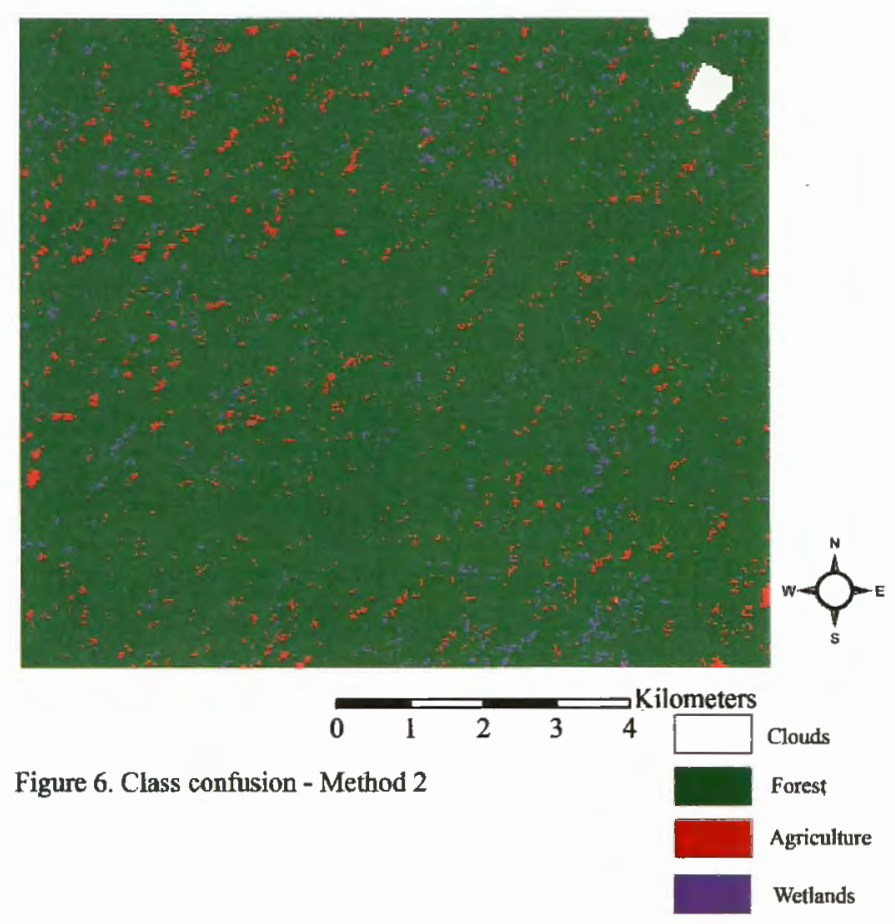

Several changes can be made that may improve the results of this study. By obtaining ground truth data or using more random sample points, accuracy can be increased. Using non-Lambertian normalization in combination with the layer merge method may also yield better results. Another approach would be to stratify the image into relatively homogenous parts and classify each part separately.

The findings from this study show that topographic correction methods can be an important component of LULC studies in mountainous regions. More research is necessary to determine which techniques are the most effective and are most suitable for particular regions, and conditions. 
Topographic correction methods can increase accuracy for land-cover classifications. Determining the best method for a particular study region requires experimentation, because there is not a single standardized method which has proven effective in all areas. In addition, it is important to realize the scale limitations that are inherent when using TM imagery for LULC change studies. Since the resolution of TM imagery is only 30 meters, some confusion between classes in a heterogeneous landscape is inevitable. The methods described in this paper should be viewed as only a small part of LULC change research. They can help identify deforestation hotspots to focus on, which can be studied more thoroughly by using finer scale imagery and fieldwork. 


\section{REFERENCES CITED}

Civco, D.L. 1989. Topographic Normalization of Landsat Thematic Mapper Digital Imagery. Photogrammetric Engineering and Remote Sensing 55 (9): 1303-1309.

Colby, J.D. 1991. Topographic Normalization in Rugged Terrain. Photogrammetric Engineering and Remote Sensing 57 (5): 531-537.

Colby, J.D., and P.L. Keating. 1998. Land Cover Classification Using Landsat TM Imagery In The Tropical Highlands: The Influence Of Ansiotropic Reflectance. International Journal of Remote Sensing 19 (8): 1479-1500.

Dorren, L.K.A., B. Maier, and A.C. Seijmonsbergen. 2003. Improved Landsat-based Forest Mapping in Steep Mountainous Terrain Using Object-based Classification. Forest Ecology and Management 183: 31-46.

Emch, M., J.W. Quinn, M. Peterson, and M. Alexander. 2005. Forest Cover Change in the Toledo District, Belize from 1975 to 1999: A Remote Sensing Approach. The Professional Geographer 57(2): 256-267.

ERDAS, 2003. ERDAS Field Guide, Seventh Edition. Atlanta, Georgia, 698 p.

Foody, G.M., R.M. Lucas, P.J. Curran, and M. Honzak. 1997. Mapping Tropical Forest Fractional Cover From Coarse Spatial Resolution Remote Sensing Imagery. Plant Ecology 131: 143-154.

Green, K., D. Kempka, and L. Lackey. 1994. Using Remote Sensing to Detect and Monitor Land-Cover and Land-Use Change. Photogrammetric Engineering \& Remote Sensing 60 (3): 331-337.

Gu, D., and A. Gillespie. 1998. Topographic Normalization of Landsat TM Images of Forest Based on Subpixel Sun-Canopy-Sensor Geometry. Remote Sensing of Environment 64: 166-175.

Hale, S.R., and B.N. Rock. 2003. Impact of Topographic Normalization on Land-Cover Classification Accuracy. Photogrammetric Engineering and Remote Sensing 69 (7): $785-791$.

Jensen. J.R. 1996. Introductory Digital Image Processing: A Remote Sensing Perspective. Upper Saddle River: Prentice Hall 
Justice, C.O., and B. Holben. 1979. Examination of Lambertian and Non-Lambertian Models for Simulating the Topographic Effect on Remotely Sensed Data. National Aeronautics and Space Administration Technical Memorandum 80557, Greenbelt, Maryland.

Lambin, E. F. 1997. Modelling and Monitoring Land-Cover Change Processes in Tropical Regions. Progress in Physical Geography 21(3): 375-393.

Lambin, E.F., H.J. Geist, and E Lepers. 2003. Dynamics of Land-Use and Land-Cover Change in Tropical Regions. Annual Review of Environmental Resources 28: $205-241$.

Leprieur, C.E., and J.M. Durand. 1988. Influence of Topography on Forest Reflectance Using Landsat Thematic Mapper and Digital Terrain Data. Photogrammetric Engineering and Remote Sensing 54 (4): 491-496.

Moran, E. F., and E. Brondizio. 1994. Integrating Amazonian Vegetation, Land-Use, and Satellite Data. Bioscience 44 (5): 329-338.

Parker, T.A., B.K. Hoist, L.H. Emmons, and J.R. Meyer. 1993. A Biological Assessment Of the Columbia River Forest Reserve, Toledo District, Belize. Washington, D.C.: Conservation International Rapid Assessment Program

Rey-Benayas, J.M., and K.O. Pope. 1995. Landscape Ecology and Diversity Patterns in the Seasonal Tropics from Landsat TM Imagery. Ecological Applications 5 (2): 386394.

Roy, P.S., B.K. Ranganath, P.G. Diwikar, T.P.S. Vohra, S.K. Bhan, I.J. Singh, and V. C. Pandian. 1991. Tropical Forest Type Mapping and Monitoring Using Remote Sensing. International Journal of Remote Sensing 12 (11): 2205-2225.

Smith, J.A., and T.L. Lin. 1980. The Lambertian Assumption and Landsat Data. Photogrammetric Engineering and Remote Sensing 46: 1183-1189.

Strahler, A.H. 1981. Stratification of Natural Vegetation for Forest and Rangeland Inventory Using Landsat Digital Imagery and Collateral Data. International Journal of Remote Sensing 2 (1): 15-41.

Teillet, P.M. 1986. Image Correction for Radiometric Effects in Remote Sensing. International Journal of Remote Sensing 7 (12): 1637-1651.

Tokola, T., J. Sarkeala, and M. Van Der Linden. 2001. Use of Topographic Correction In Landsat TM-based Forest Interpretation in Nepal. International Journal of Remote Sensing 22 (4): 551-563. 
Tucker, C.J., and J.R.G. Townshend. 2000. Strategies for Monitoring Tropical Deforestation Using Satellite Data. International Journal of Remote Sensing 21 (6 \& 7): 1461-1471.

Turner, B. L. II, W. B. Meyer, and D. L. Skole. 1994 Global Land-Use/Land-Cover Change: Towards An Integrated Study. Ambio 23 (1): 91-95.

Wulder, M.A., S.E. Franklin, J.C. White, M.M. Cranny, and J.A. Dechka. 2004. Inclusion of Topographic Variables in an Unsupervised Classification of Satellite Imagery. Canadian Journal of Remote Sensing 30 (2): 137-149. 